American Journal of Applied Sciences 9 (1): 60-65, 2012

ISSN 1546-9239

(C) 2012 Science Publications

\title{
Equity Valuation with the Use of Multiples
}

\author{
${ }^{1}$ Stauropoulos Antonios, ${ }^{1}$ Samaras Ioannis and ${ }^{2}$ Arsenos Panagiotis \\ ${ }^{1}$ Department of Applied Informatics, University of Macedonia, \\ 156 Egnatia Str, P.O Box 1591540 06, Thessaloniki Greece \\ ${ }^{2}$ Department of Business Administration, TEI of Ionian Islands
}

\begin{abstract}
Problem statement: Equity valuation with the use of multiples is widely used by academics and practitioners concerning its functionality. This study aims to explore the sensitivity of three multiples in terms of bias. Approach: The three multiples under consideration are the Price-To-Sales $(\mathrm{P} / \mathrm{S})$ multiple, the Price-To-Book value of equity (P/B) multiple and the Price-To-Earnings (P/E) multiple using both current and one-year-ahead earnings forecasts. Results: According to the empirical results, the multiples $\mathrm{P} / \mathrm{mdfy} 1$ and $\mathrm{P} / \mathrm{mnfy} 1$ are considered to be biased, with their means being negatively biased and their medians being positively biased. The results can be considered as reliable owing to the large sample and the procedure followed for its selection. Conclusion: This study offers a better understanding of the valuation approach through the use of multiples, in order analysts assumption to be more carefully and properly chosen and their results to be more accurately produced.
\end{abstract}

Key words: Equity valuation, multiples under examination, terms of bias, value relevance, Price-ToEarnings $(\mathrm{P} / \mathrm{E})$, Price-To-Book $(\mathrm{P} / \mathrm{B})$, Price-To-Sales $(\mathrm{P} / \mathrm{S})$, discounted cash, intrinsic value, marginal information, valuation models, Residual Income Valuation Model (RIVM)

\section{INTRODUCTION}

Fundamental analysis or valuation is the convertibility of an analyst's prediction or a firm's element into value and it is regarded as the upper stage of a firm's prospective analysis (Palepu et al., 2003).

The significance of accounting numbers in valuation process is inarguable, something that is sustained by the imperfectness and uncertainty of the markets (Burgstahler and Dichev, 1997).

Furthermore, accounting numbers have a strong linkage with several valuation methods, such as Residual Income Valuation Model (RIVM) or Abnormal Earnings (AE), Discounted Cash Flows (DCF), Dividend Discount Model (DIVM) and the multiples method that consist the basis for this study.

Finally, according to the multiple-based approach, it is used in a wide range by academics and practitioners due to its simplicity (Lie and Lie, 2002). The most commonly used multiples are the Price-toEarnings (P/E), Price-to-Book value (P/B), Price-ToSales (P/S) and Price-to-Cash Flow from Operations (P/CFO). The evaluation of multiples can be achieved through the use of two methods; multiple comparison analysis and multiple screening method.
This study refers to the sensitivity of three multiples, which are Price-To Sales (P/S) multiple, Price-to-Book value of equity (P/B) multiple and Priceto-Earnings $(\mathrm{P} / \mathrm{E})$ multiple using both current and oneyear-ahead earnings forecasts (that is, price to current EPS, price to mean of one-year-ahead earnings forecast and price to median of one-year-head earnings forecast) in terms of bias. The main purpose is to examine the relative performance of these three multiples, while a further objective is to explore whether analysts are biased or not.

The sensitivity of price multiples as valuation model is being tested by a few academic articles. Consequently, the goal of the present study is to fill this gap in literature and contribute in the field through the production of reliable, effective and easy generalized results.

The sample consists of 3,572 US listed companies after the implementation of a number of filters in an initial sample of 5,987 firms. The performance of parametric tests was conducted, in order a time-series analysis of the above multiples to be carried out. Additionally, it was tested statistically; the significant differentiation of the real price from the average intrinsic value and it was conducted T-test analysis and regression analysis at 5\% level of significance.

Corresponding Author: Ioannis Samaras, Department of Applied Informatics, University of Macedonia, 156 Egnatia str,

P.O Box 1591540 06, Thessaloniki Greece Tel: +302310 891862 
Am. J. Applied Sci., 9 (1): 60-65, 2012

The intention of the present study is to add a better understanding over the multiple-based valuation approach helping analysts in choosing more carefully and properly the best assumption and conclude in the production of improved and more precise results.

\section{Literature review:}

Value relevance of accounting measures: The value relevance term, is used with reference to the sufficiency of the summary accounting numbers in order to achieve the underlying economic value of the firm which we measure through current stock prices. In the foretime, value relevance issues have been examined by researchers through the use of levels (prices) or changes (returns) reports (Athianos et al., 2005; Athianos and Vasakidis 2006; Vasakidis and Athianos, 2010). Kothari and Zimmerman (1995) mentioned that the return specification is less convenient than the price specification. Moreover, price specification is capable of measuring the value relevance of both the flow (net income or earnings) and the stock (book value) variables. The IASs are assumed to have the possibility of harmonization (Athianos et al., 2007), by improving the value relevance of book values at the expense of net income. On the other hand, price specification disadvantage is the vulnerability to econometric problems, derived from heteroskedasticity and scale bias (Kothari and Zimmerman, 1995).

With respect to many studies on the English literature, two distinct opinions are presented. Particularly, many researches maintain the value relevance of accounting earnings (Ball and Brown, 1968; Collins and Kothari, 1989; Kothari and Zimmerman, 1995) whereas other studies support the association of the stock price with the book value of firm assets, sustaining that measures of assets and liabilities indicate the expected results of future activities (Barth, 1991). The above studies make use of models that rely either on earnings or book value which are assumed as alternative approaches of valuation models (Barth and Landsman, 1995; Solomons, 1995).

According to recent studies, accounting systems are capable of obtaining information about book value and earnings, which are supplementary components of equity value (Chang, 1999; Fetham and Olson, 1995; Pennman, 1998). In reference to Burgstahler and Dichev (1997), based an adaptation value and recursion value, the book value does not obtain the net value of the firm's recourses mostly under the historical cost and it is irrelevant with the success of the firm's employment of its resources. Contrarily, earnings reflect the value measurement, which estimate the results of employing firm's resources. Therefore, valuation models with many variables are more preferable than models with one variable.
In order our value relevance analysis to be clearer, we rank the value relevance research into three categories (Holthausen and Watts, 2001): (1) relative association studies, (2) incremental association studies, (3) marginal information studies.

According to the relative association studies, stock market values or returns are compared with the alternative bottom-line measures. This type of study investigates, where the greatest association exists, between earnings numbers that are reported under an accounting standard or market values and returns reported under the existing GAAP (Dhaliwal et al., 1999). Other studies are testing the association between the comparison of foreign GAAP and U.S. GAAP earnings. In these studies the parameter examined is the difference in the $\mathrm{R}^{2}$ of regressions by using different bottom line accounting numbers. The most value relevant accounting number is the one with the larger $\mathrm{R}^{2}$.

The incremental association studies investigate if it is more helpful the explanation of value or returns considering other specified variables. The value relevance of accounting numbers is obtained, if its estimated regression coefficient is significantly different from zero. In reference to the study of Vencatachalam (1996), it is also examined if the coefficient on the fair value of derivatives is significantly different from one.

Finally, the marginal information context studies, provides investors with relevant information through the investigation of specific accounting numbers. Based on these studies, value changes rely on event studies for the determination of specific accounting numbers. The price reactions are considered evidence of value relevance.

Multiples: The acceptance of a valuation technique relies on the advantages that overcome the benefit of using it. A full-fledged primal analysis may become costly due to the considerable amount of information that is required from the analyst, which generates remarkable effort. A response to that situation was the development of multiple analysis (Penman, 2005). Multiple analysis is relevant to practitioners, such as investment bankers and analysts, in order to be used in the company valuation but also to academic researchers (Lie and Lie, 2002).

In reference to Palepu et al. (2003), multiple-based valuation methods are developed by analysts in a wide range. The simplicity of multiples is the main purpose of their popularity. The fundamental diversification between multiples and other methods (discounted cash flows, discounted dividends, discounted abnormal earnings), is that with reference in a variety of parameters such as growth, profitability and cost of capital, there is no demand for extended multiple-year forecast. 
According to Bhojraj and Lee (2002), multiple based analysis is the most commonly used method in equity valuation. Multiples are widespread in the statements and recommendations of the sell-side financial analysts and moreover are broadly utilized in investment bankers' fairness aspects. Furthermore, the implementation of multiples can be helpful in accordance with Initial Price Offerings (IPO), Seasoned Equity Offering (SEO), leveraged buyout transactions and other activities in association with merger and acquisition (M\&A). Even advocates of projected Discounted Cash Flows (DCF) valuation methods often estimate the terminal values with the contribution of market multiples.

Calculation of multiples: The most prevalent multiples are the price-to-earnings $(\mathrm{P} / \mathrm{E})$, the price-to-book value $(\mathrm{P} / \mathrm{B})$, the price-to-sales $(\mathrm{P} / \mathrm{S})$ and the price-to-cash flow from operations (P/CFO). The evaluation of multiples can be accomplished by the use of two methods; the method of multiple comparison analysis and multiple screening method. The multiple comparison analysis consists of three steps. Firstly, recognition of comparable firms whose operations are closely related to those of the target firm that their value is controversial. Secondly, recognition of measures in the financial statement of the comparable firm, such as earnings, book value, sales, cash flows and calculation of multiples with those measures. Thirdly, application of the average or median of these multiples to the relative measure for the target firm, aiming to get the value of the target firm (Penman, 2005).

\section{MATERIALS AND METHODS}

Sample selection: The sample constitutes by a set of US listed companies of all industries except financial industry. The initial sample consists of 5,987 firms. After applying a number of filters the sample was gradually reduced. Firstly, it was decided to include in the final sample only firms whose balance sheets' closing month was in December between 2001 and 2003. Secondly, it was decided to exclude those companies whose data regarding sale, EPS, forecasted EPS mean, median and book value were not available. Hence, the sample was reduced to 3,572 companies. Hereafter, the intrinsic values were calculated for the companies of the final sample. Since each multiple has different characteristics, withsorising and trimming was used for different multiples.

This sample was obtained by COMPUSTAT database, whereas the data regarding the cash flow statements was derived from the I/B/E/S database and, as mentioned before, concerning the fiscal year 2001, 2002 and 2003.
In particular, for $\mathrm{P} / \mathrm{S}$ and $\mathrm{P} / \mathrm{B}$ ook value, it was used $10 \%$ trimming of the top values so as to avoid negative prices. For the EPS, mnfy1 and mdfy1, is was decided to exclude those firms with negative intrinsic value and also a 5\% trimming was used to the top and bottom values of each one of them. The main reason for adopting such a method is to avoid extreme values resulting from high levels of profitability and sales.

Research and hypotheses development: This chapter consists of five subsections which describe the research methodology adopted. Specifically, this chapter includes the description of the research questions, the research paradigm, the research design, the sample selection and the definition of the comparable firms. Finally, it also provides some descriptive statistics for the value drivers of the sample.

Research questions: After taking into consideration prior research in the field of valuation methods and constructing the hypothesis of this study, a research question also try to address:

"Are the multiples under examination positively or negatively biased?"

Research design: The multiple-based approach examined in this study is a relative valuation approach (Bhojraj and Lee, 2002). Even though literature suggests the use of harmonic mean in calculating the multiples owing to its superiority in comparison to median capitalization rate (Liu et al., 2002; Beatty et al., 1999), the present study employees the median.

The use of median capitalization rate was mainly decided so as to avoid a possible negative impact on the performance of multiples in case where harmonic mean was used instead. Besides, Alford (1992) uses the same method, that is, median capitalization rate, to lessen the impact of extreme multiples.

Current Earnings Per Share (EPS) and one-yearahead earnings per share forecasts are selected as value drivers. Consequently, a valid comparison of the value relevance and actual performance of these value drivers is achieved. Liu et al. (2002) argue that longer forecast reflect more value relevant information. However, oneyear-ahead EPS forecasts were employed instead of two-year-ahead EPS forecasts for simplicity reasons and owing to the sample size.

As for the collection of the data concerning current and forecasted EPS, it was conducted from Institutional Broker's Estimation System database (I/B/E/S). The 
variables which represent this multiples are actual and mnfy1 and mdfy1 respectively.

Since forecasted earnings are derived from different analysts, mnfy1 (mean) and mdfy1 (median) of all analyst's forecasts were employed in order to explore whether potential bias in earnings forecasts affect the results of the valuation.

According to Alford (1992), bias can be defined as the price scaled difference between the value estimate and the current security prices.

The estimation formula for bias is provided by Alford (1992) as follows:

\section{Bias:}

$e_{i, t}=\frac{V_{t}^{E}-P_{i, t}}{P_{i, t}}$

Where:

$V_{t}=$ The intrinsic value of the $i^{\text {th }}$ security

$\mathrm{P}=$ The realized security price

$\mathrm{a}_{\mathrm{i}}=$ The intercept

$\beta_{\mathrm{i}}=$ The beta coefficient

\section{RESULTS AND DISCUSSION}

Descriptive statistic statistics of value drivers timeseries security prices and $\mathrm{P} / \mathrm{B}$ ratio after the 5 trimming used to the current EPS are reported in Table 1 Furthermore, a $10 \%$ trimming was used so as to avoid negatively skewed variables.

According to the figures presented in Table 1, all the variables are positively skewed with high levels of concentration as indicated by kurtosis. The mean and the median of the mean of on-year-ahead consensus analysts' forecasts and of the equivalent median are quite similar suggesting no bias in analysts' forecasts. Therefore, it is clear that no statistical difference is expected to exist, by choosing between the mean and the median of the earnings forecasts, regarding the performance of $\mathrm{P} / \mathrm{E}$ multiple.

\section{Multiples' evaluation in terms of bias:}

Two sample parametric t-test: Before analyzing the results regarding the evaluation of multiples under accuracy and bias, it is essential to mention the results of the two-sample parametric t-test undertaken. The use of the parametric t-test enables the means of the intrinsic value and the stock price produced to be compared to each other. In particular, it is tested if there is a statistically significant difference between the two parameters and thus, if the stock price is under or overestimated.

The results of the two-sample parametric t-test of the multiples' means and medians, as illustrated in Table 2, suggest that among the five multiples under examination, the mean P/mdfy 1 and the median P/S perform better; owing to the fact, that both multiples estimate the stock value well enough on average and their significance level suggests that on average the multiples does not misprice the stock (P/mdfy1: $\mathrm{p}=$ $0.621, \mathrm{P} / \mathrm{S}: \mathrm{p}=0.407$; which are greater than 0.025 significance level).

As far as P/current EPS is concerned, the mean and the median of the multiple, indicate that the multiples systematically underestimated the stock value, due to the mean stock price which is greater than the mean intrinsic value. However, the difference between the means of the stock price and the intrinsic value of the mean P/current EPS multiple is not statistically significant since the $\mathrm{p}$ value equals 0.140 which is higher than the significance level. On the other hand, the median P/current EPS multiple has a statistically significant difference $(\mathrm{p}<0.0001)$.

Table 1: Descriptive statistics

\begin{tabular}{lrrrrr}
\hline $\begin{array}{l}\text { Value } \\
\text { drivers }\end{array}$ & \multicolumn{1}{c}{ Mean } & \multicolumn{1}{c}{ Median } & SD & Skewness & Kurtosis \\
\hline Current & 0.529 & 0.660 & 3.171 & 6.6610 & 196.150 \\
EPS & & & & & \\
Mdfy1 & 1.144 & 0.950 & 1.552 & 3.9710 & 76.609 \\
Mnfy1 & 1.145 & 0.960 & 1.548 & 4.0070 & 76.010 \\
Sales & 3595.380 & 6880.830 & 11511.850 & 10.433 & 151.654 \\
P4 & 24.418 & 19.950 & 28.213 & 16.635 & 360.467 \\
P/B & 3.528 & 1.987 & 34.173 & 52.745 & 2422.370 \\
\hline
\end{tabular}

Notes: Current EPS: Current Earnings per Share as mentioned by DATA 58 in COMPUSTAT terms,Mndfy1: the mean of one-yearahead consensus analysts' forecasts in terms of $\mathrm{I} / \mathrm{B} / \mathrm{E} / \mathrm{S}$ for each firm. Mdfy1: the median of one-year-ahead consensus analysts' forecasts in terms of $\mathrm{I} / \mathrm{B} / \mathrm{E} / \mathrm{S}$ for each firm.Sales: net sales as mentioned by DATA 12 in COMPUSTAT terms.P/B: the price-to-book ratio of each firm

Table 2: Two sample parametric t-test

\begin{tabular}{lclr}
\hline Multiples & $\begin{array}{l}\text { Mean of } \\
\text { intrinsic value }\end{array}$ & $\begin{array}{l}\text { Mean of } \\
\text { stock price }\end{array}$ & P-value \\
\hline Mean P/current EPS & 26.526 & 27.347 & 0.1400 \\
Median P/current EPS & 22.976 & 28.216 & $<0.0001$ \\
Mean P/mdfy1 & 25.927 & 25.688 & 0.6210 \\
Median P/mdfy1 & 24.630 & 26.280 & 0.0003 \\
Mean P/mnfy1 & 26.482 & 25.563 & 0.0620 \\
Median P/mnfy1 & 24.377 & 26.089 & 0.0002 \\
Mean P/S & 22.725 & 19.863 & $<0.0001$ \\
Median P/S & 22.380 & 22.036 & 0.4070 \\
Mean P/book value & 53.710 & 18.210 & $<0.0001$ \\
Median P/book value & 428.365 & 24.417 & $<0.0001$
\end{tabular}


Am. J. Applied Sci., 9 (1): 60-65, 2012

Table 3: Evaluation in terms of Bias

\begin{tabular}{llll}
\hline Multiples & Mean of bias & $\begin{array}{l}\text { P-value } \\
\text { of t-test }\end{array}$ & Typical error \\
\hline Mean P/current EPS & -0.088 & 0.042 & 0.021 \\
Median P/current EPS & -0.153 & 0.028 & 0.014 \\
Mean P/mdfy1 & -0.065 & 0.022 & 0.012 \\
Median P/mdfy1 & 0.035 & 0.017 & 0.008 \\
Mean P/mnfy1 & -0.085 & 0.024 & 0.012 \\
Median P/mnfy1 & 0.045 & 0.017 & 0.008 \\
Mean P/S & -0.824 & 0.110 & 0.056 \\
Median P/S & -0.382 & 0.066 & 0.033 \\
Mean P/book value & -2.925 & 0.122 & 0.062 \\
Median P/book value & -26.199 & 2.841 & 1.449 \\
\hline
\end{tabular}

According to the mean $\mathrm{P} / \mathrm{mnfy} 1$, it is implied that the multiple is systematically overestimating the stock value. Yet, the stock is not mispriced as shown by the significance level which is higher than the required one $(\mathrm{p}=0.062)$. On the contrary, the median of the same multiple is systematically underestimating the stock, presenting a difference between the means which is statistically significant $(p<0.025$ significance level).

Regarding the $\mathrm{P} / \mathrm{book}$ value multiple, both the mean and the median of the particular multiple have the same performance. Specifically, the P/book value multiple is systematically overestimating the stock price, indicating a difference between the means of the stock price and the intrinsic value which is statistically significant $(\mathrm{p}=0.0001)$.

Finally, the median of the P/mdfy1, as shown in Table 2, implies that the multiple systematically underestimated the stock value and that the difference among the means is statistically significant $(p<0.025$ significance level). On the contrary, the mean $\mathrm{P} / \mathrm{S}$ is overestimating the stock value systematically, but it has the same significant performance as the P/mdfy 1 .

Bias: The performance measurement of the valuation approaches in terms of accuracy and bias is presented in unified manner to facilitate direct comparison of the multiples due to similarities they reflect as performance metrics. Table 3 contains descriptive statistics of both absolute and signed valuation error differences among them, along with their statistical significance.

The Table 3 shows that on average all multiples are unbiased, owing to the statistically insignificance. Particularly, in terms of bias with a significance level being equal to 2.5 per cent, the p-value of $t$-test for the mean P/current EPS and the median P/current EPS equals to 0.042 and 0.028 respectively.

Similar performance has been recorded by the rest of the unbiased multiples, indicating a greater t-test $\mathrm{p}$ value than that of the significance level required. Specifically, $p$-value of the mean P/S equals to 0.110 , $\mathrm{p}$-value of the median P/S equals to 0.066, p-value of the mean P/book value equals to 0.122 and $\mathrm{p}$-value of the median $\mathrm{P} / \mathrm{book}$ value is equal to 2.841 ; all of these p-values imply a greater price than that of the significance level and therefore are unbiased.

On the other hand, two out of the five multiples analyzed, seem to be statistically biased. Particularly, the median of one-year-ahead forecasted earnings (mdfy1) and the mean of one-year-ahead forecasted earnings (mnfyl) are the biased value drivers. More specifically, according to the mean $\mathrm{P} / \mathrm{mnfy} 1$ multiple, it is implied that the multiple is statistically significant with a p-value equal to 0.024 . Furthermore, the mean of bias has a negative sign which indicates that the multiple underestimates on average the stock value, suggesting that there is other value relevant information.

Contrarily, the median $\mathrm{P} / \mathrm{mnfy} 1$, although it is statistically significant with a p-value smaller than the significance level $(p=0.017)$, the mean of bias has a positive sign which indicated that the multiple overestimates on average the stock value.

Finally, in reference to the mean on P/mdfy 1 , it indicates that the multiple is statistically significant; the significance level is greater than the p-value of the multiple $(p=0.022)$. The particular multiple's mean of bias has a negative sign, suggesting than on average the stock value is underestimated by the multiple, implying that there are other value relevant information that are not included. Moreover, similar performance is recorded by the median $\mathrm{P} / \mathrm{mdfy} 1$; suggesting that the multiple is biased, but the mean of bias has a positive sign, indicating that the multiple overestimates on average the value of the stock.

\section{CONCLUSION}

The results of the valuation of multiples in terms of bias indicates the multiples price-to-current EPS, priceto-book value and price-to-sales as better performers. However, since bias indicates more than one multiples as good performers, the classification is conducted according the results of explainability. Therefore, the multiple identified as the one with the better performance in comparison with the others is the priceto-sales multiple, when evaluating the multiples' means and the price-to-book value multiple, when evaluating the multiples' medians. It should be mentioned, though, that the identification of $\mathrm{P} / \mathrm{book}$ value as the best performer contrasts the results of Cheng and McNamara (2000), which imply that, for most definitions of comparable firms, the $\mathrm{P} / \mathrm{E}$ valuation method performs better than the $\mathrm{P} / \mathrm{book}$ value valuation method. 


\section{REFERENCES}

Alford, A.W., 1992. The effect of a set of comparable firms on the accuracy of the price-earnings valuation method. J. Account. Res., 30: 94-108.

Athianos, S. and A. Vasakidis, 2006. How the adoption of international accounting standards affects financial statements: The case of early adoption by Greek listed companies. Int. Rev. Applied Econ. Res., 1: 205-220.

Athianos, S., A. Vazakidis and N. Dritsakis, 2005. Financial statement effects of adopting international accounting standards: The case of Greece. 4th Conference of the Hellenic Finance and Accounting Association Hellenic Finance and Accounting Association, Dec. 16-17, University of Pireaus, Piraeus, Greece.

Athianos, S., A. Vazakidis and P. Arsenos, 2007. The accounting harmonization after the adoption of IAS'S/IFRS'S the case of Greek listed companies. Int. Rev. Applied Econ., 2: 31-67.

Ball, R. and P. Brown, 1968. An empirical evaluation of accounting income numbers. J. Account. Res., 6: 159-178.

Barth, M.E. and W.R. Landsman, 1995. Fundamental issues related to using fair value accounting for financial reporting. Account. Horizons, 9: 97-107.

Barth, M.E., 1991. Relative measurement errors among alternative pension asset and liability measures. Account. Rev., 66: 433-463.

Beatty, R.P., S.M. Riffe and R. Thompson, 1999. The method of comparables and tax court valuations of private firms: An empirical investigation. Account. Horizons, 13: 177-199. DOI: 10.2308/acch.1999.13.3.177

Bhojraj, S. and C.M.C. Lee, 2002. Who is my Peer? A valuation-based approach to the selection of comparable firms. J. Account. Res., 10: 407-439. DOI: 10.1111/1475-679X.00054

Burgstahler, D.C. and I.D. Dichev, 1997. Earnings, adaptation and equity value. Account. Rev., 72: 187-215.

Chang, J.J., 1999. The decline in value relevance of earnings and book values. Thesis D.B.A., Harvard University, Graduate School of Business Administration.

Cheng, C.S.A. and R. McNamara, 2000. The valuation accuracy of the price-earnings and price-book benchmark valuation methods. Rev. Quan. Finance Account., 15: 349-370. DOI: 10.1023/A: 1012050524545
Collins, D.W. and S.P. Kothari, 1989. An analysis of intertemporal and cross-sectional determinants of earnings response coefficients. J. Account. Econ., 11: 143-183. DOI: 10.1016/0165-4101(89)90004-9

Dhaliwal, D., K.R. Subramanyem and R. Trezevant, 1999. Is comprehensive income superior to net income as a measure of firm performance? J. Account. Econ., 26: 43-67. DOI: 10.1016/S01654101(98)00033-0

Fetham, G.A. and J.A. Olson, 1995. Valuation and clean surplus accounting for operating and financial activities. Contemporary Account. Res., 11: 689-731. DOI: 10.1111/j.19113846.1995.tb00462.x

Holthausen, R.W. and R.L. Watts, 2001. The relevance of the value relevance literature for financial accounting standard setting. J. Account. Econ., 31: 3-75. DOI: $10.2139 /$ ssrn.228950

Kothari, S.P. and J.L. Zimmerman, 1995. Price and return models. J. Account. Econ., 20: 155-192. DOI: 10.1016/0165-4101(95)00399-4

Lie, E. and H.J. Lie, 2002. Multiples used to estimate corporate value. Finan. Anal. J., 58: 44-54.

Liu, J., D. Nissim and J. Thomas, 2002. Equity valuation using multiples. J. Account. Res., 40: 135-172. DOI: 10.1111/1475-679X.00042

Palepu, K.G., P.M. Healy and V.L. Bernard, 2003. Business Analysis and Valuation: Using Financial Statements. 3rd Edn., Thomson South-Western, ISBN-10: 0324118945, pp: 928.

Penman, S.H., 2005. Discussion of "on accountingbased valuation formulae" and "expected EPS and EPS growthas determinants of value". Rev. Account. Stud., 10: 367-378. DOI: 10.1007/s11142-005-1536-2

Pennman, S.H., 1998. Combining earnings and book value in equity valuation. Contemp. Account. Res., 15: 291-324. DOI: $10.1111 / \mathrm{j} .1911-$ 3846.1998.tb00562.x

Solomons, D., 1995. Criteria for choosing an accounting model. Account. Horizons, 9: 42-51.

Vasakidis, A. and S. Athianos, 2010. Measuring investors' reaction to the adoption of international financial reporting standards in Greece, using a market-based model. Am. J. Econ. Bus. Admin., 2: 103-112. DOI: 10.3844/ajebasp.2010.103.112

Vencatachalam, M., 1996. Value-relevance of banks' derivatives disclosures. J. Account. Econ., 22: 327355. DOI: 10.1016/S0165-4101(96)00433-8 